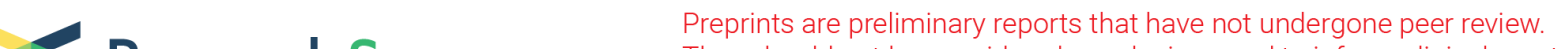 $\begin{array}{ll}\text { Research Square } & \text { They should not be considered conclusive, used to inform clinical practice, } \\ \text { or referenced by the media as validated information. }\end{array}$
}

\section{A Multi-Site Study of Mental Disorders in the Mozambican Health Care System}

\section{Lidia Gouveia ( $\nabla$ vovotetchauque@gmail.com )}

Department of Mental Health, Ministry of Health https://orcid.org/0000-0001-9746-8627

\section{Kathryn Lovero}

State University of New York

\section{Wilza Fumo}

Mozambique Department of Mental Health

Afonso Mazine Tiago Fumo

Mozambique Department of Mental Health

\section{Palmira Dos Santos}

Mozambique Department of Mental Health Mental Retardation and Substance Abuse Services:

Department of Behavioral Health and Developmental Services

\section{Ana Olga Mocumbi}

Mozambique National Institute of Health

\section{Maria A. Oquendo}

University of Pennsylvania Perelman School of Medicine

Jair J. Mari

UNIFESP: Universidade Federal de Sao Paulo

\section{Milton Wainberg}

New York State Psychiatric Institute

\section{Cristiane Duarte}

New York State Psychiatric Institute

\section{Research}

Keywords: mental health, low- and middle-income countries, task-sharing, integrated care, substance use disorder

Posted Date: October 7th, 2020

DOI: https://doi.org/10.21203/rs.3.rs-85842/v1

License: (c) (i) This work is licensed under a Creative Commons Attribution 4.0 International License. Read Full License 


\section{Abstract}

\section{Background}

In Mozambique, human and financial resources for public mental health services are extremely limited. Understanding the mental health needs of those seeking healthcare can inform efficient targeting of mental health services. We examined if the frequency of mental disorders in a health facility varied based on the level of specialization of such facility, from primary care without mental health specialists ( $\mathrm{PrCMH}-)$, to those with mental health specialists $(\mathrm{PrCMH}+)$ and tertiary care (TerC), where both inpatient and outpatient mental health services are available.

\section{Methods}

Participants were adults seeking health or mental health services at six facilities ( $2 \mathrm{PrCMH}+, 3 \mathrm{PrCMH}$-, and 1 TerC) in the cities of Maputo and Nampula in Mozambique. Mental disorders were assessed by the MINI International Neuropsychiatric Interview (MINI) 4.0.0. We compared the sociodemographic characteristics and MINI diagnoses across the three types of health facilities. Multiple logistic regression models determined the likelihood that a person seeking services at each type of facility would have any mental disorder, common mental disorders (CMD), severe mental disorders (SMD), substance use disorders (SUD), and moderate-to-high suicide risk, adjusting for sociodemographic factors.

\section{Results}

Of the 612 total participants, $52.6 \%(n=322)$ were positive for at least one mental disorder: $37.1 \%$ were positive for CMD, $28.9 \%$ for SMD, $13.2 \%$ for SUD, and $10.5 \%$ had suicide risk. Presence of any mental disorder was highest in TerC (62.5\%) and lowest in $\mathrm{PrCMH}-(48.4 \%)$. Adjusting for sociodemographic covariates, participants in PrCMH+ were significantly more likely to have SMD (OR: 1.85, 95\% Cl: 1.103.11) and SUD (OR: 2.79, 95\% Cl: 1.31-5.94) than participants in PrCMH-; participants in TerC were more likely to have CMD (OR: $1.70,95 \% \mathrm{Cl}$ : 1.01-2.87) and SUD (OR: 2.57, 95\%Cl: 1.14-5.79) than in PrCMH-. Suicide risk was the only condition that did not differ across facility types.

\section{Conclusions}

As anticipated, people with mental disorders were more likely to be cared for at facilities with mental health specialists. However, our study suggests there is a remarkably high frequency of mental disorders across different types of facilities within the Mozambican healthcare system. These results suggest a need to increase mental health services at the primary care level.

\section{Background}

Current efforts to close the mental health treatment gap have focused on task-shifting and integration of services within primary care settings. In low- and middle-income income countries (LMIC), inequalities in access to health services, difficulties in integrating mental health services into primary health care, 
inefficiencies in the use of services and scarce resources are barriers to access to mental health care (1). To properly target minimal resources in LMIC, it is critical to understand the demographic profile and mental health needs of patients served in different types of clinics within the health care system.

Mozambique is one of the poorest countries in the world, with a human development index in the "low development" category that ranks it in the 180th position of 189 countries (2). It has a population of over 29 million, with an annual growth rate of $2.46 \%$ and a life expectancy at birth of 54.4 years. The literacy rate is $58.0 \%$ for the total population; $73.3 \%$ for men and $45.4 \%$ for women (3). The country is mostly rural, with $70 \%$ of the population living and working in rural areas. The annual per capita income is US $\$ 460$ but approximately $70 \%$ of the population lives below the poverty line with an income below US $\$ 0.40$ per day (< US $\$ 146$ per year) (2).

The Mozambican National Health System (Serviço Nacional de Saúde) has approximately 5.07 physicians and 84 beds per 100,000 inhabitants, compared to an average of 30 physicians per 100,000 for low income countries. There are 1,249 primary health care units, which are not sufficient to cover the health care needs of the country's population (4). Like other LMIC (5), resources dedicated to mental health services are even more limited, with just 0.06 psychiatrists and 0.78 psychiatric beds per 100,000 inhabitants (6). For context, the Organization for Economic Cooperation and Development recommends 15 psychiatrists per 100,000 inhabitants (7).

Faced with this gap in mental health treatment capacity, in 1993, the Mozambican Ministry of Health (MISAU), Department of Mental Health, created a national strategy and a sustainable action plan with guidelines for implementation and transfer of competencies (task-shifting) for provision of neuropsychiatric services to a new type of mental health specialist, Psychiatric Technicians. These technicians are mid-level professionals, trained in a 30-month program to conduct community-based mental health and epilepsy prevention and promotion activities; recognize, diagnose and treat neuropsychiatric disorders; provide counselling, psychosocial support and brief psychotherapy; design and implement community-based follow-up programs; and prescribe psychotropic and antiepileptic drugs according to the prescription level of the National Drug Formulary under the supervision of psychiatrists. Of note, this program was developed and implemented before the terms task shifting and task sharing were coined. $(6,8)$

The Mozambican national mental health system aims to offer the majority of its mental health services in primary care units $(6,9)$. In the majority of provinces, when mental health services are not available at a primary care unit, which is the rule, patients are referred to the next levels of care-secondary (district level), tertiary (province level) or quaternary (in one of the four central hospitals or in one of the two psychiatric hospitals in the country) - depending on the severity of patients' conditions and need for inpatient treatment. At the secondary, tertiary, and quaternary levels of care, mental health services may include inpatient and outpatient services. The difference between the levels of care is the availability of resources, with more multidisciplinary mental health teams and more beds occupied by patients with psychiatric conditions as the level of care increases. At the primary care level, there are no beds and, in 
some cases, mental health services are provided by psychiatric technicians and, in other cases, there are no specialized mental health services and psychiatric patients are referred to the next levels of care. At the secondary/district level, there are four beds for psychiatric patients in each facility and psychiatry technicians most often provide mental health services, though in a few sites, a psychologist may provide care at the secondary level as well. At the tertiary/provincial level, there are eight beds for psychiatric patients in each facility and mental health services are provided by a multidisciplinary team, including a psychiatry technician, a psychologist, and, in some cases, an occupational therapist and a psychiatrist. At the quaternary level, in each of the five facilities nationwide, there are specialized mental health units with 30 or more beds and mental health services are provided by a team including a psychiatric technician, psychologist, occupational therapist, and psychiatrist.

With the development of the Psychiatric Technician program, Mozambique has designed and implemented a feasible and sustainable way to provide public mental health services despite scarce human resources and negligible budgets through task shifting. Yet, as mental health human resources are still insufficient, knowing how different types of mental health problems may vary across different types of primary care settings remains crucial to proper allocation of limited resources. Most prior studies quantifying the burden of mental disorders in $\operatorname{LMIC}(10,11)$ were population-based and utilized screening tools. Rarely have studies focused on the primary care setting, where interventions are likely to occur. Particularly, studies that performed a more in-depth characterization of mental disorders, by relying on a diagnostic structured interview, rather than on screening tools are needed. Although there are prevalence estimates for mental disorders for Mozambique based on global studies (5), large-scale population-based studies of a wide range of mental disorders have not been conducted in Mozambique.

This study examines how the frequencies of mental disorders vary along a spectrum of types of health care facilities where patients with mental disorders could be identified and receive care in Mozambique: five primary care units (some including mental health specialists and some not) and a tertiary care unit (where more specialized psychiatric care is available). We hypothesized that more severe psychiatric disorders would be found in tertiary care followed by primary care with and then without specialists, reflecting the level of specialty mental health care available and existing referral pathways in these settings, regardless of differences in socioeconomic conditions across the different settings studied.

The data for this report originates from a study that had as its primary goal to develop a low-burden, effective screening tool for the practical identification of common and severe mental disorders in lowresource settings (12). The data generated as part of this study is, to date, the most comprehensive source of information about mental disorders in the public health system of care in Mozambique.

\section{Methods}

\section{Study setting}


We conducted a cross-sectional study at health facilities in the cities of Maputo and Nampula, located in the southern and northern regions of the country, respectively. Maputo is the country's capital and second most populous city and has better overall socioeconomic indicators than Nampula and nationwide estimates. Conversely, the socioeconomic indicators for Nampula, a city in a largely rural province, which is the country's most populous, are like nationwide estimates (National Census - $2007 \& 2017$ ). In Maputo, mental health care is mostly provided at the primary, secondary, and tertiary levels, with only the most severe cases using quaternary care. Nampula represents an extreme of the system, as in this city mental health services are only present in quaternary care settings.

In Maputo, the study took place at two primary care facilities with mental health specialists ( $\mathrm{PrCMH}+$ ) (Albazine and Xipamanine Health Centers) and one tertiary care facility (TerC) (Mavalane General Hospital). These three health facilities have departments for outpatient mental health, maternal and child health, chronic diseases, infectious disease screening, and emergency care; the Mavalane General Hospital also has the Center for Integrated Care for Victims of Violence and inpatient psychiatric services. Mavalane Hospital in Maputo has one psychiatrist, eleven psychologists, and three psychiatric technicians on staff/site; the two primary care units in Maputo each have a psychologist and psychiatric technician on staff/site. In Nampula city, the study took place in three primary care facilities without mental health specialists (PrCMH-) ( $1^{\circ}$ de Maio, 25 de Setembro and Muhala Expansão Health Centers). These three health facilities have departments for maternal and child health, chronic diseases, infectious diseases, and emergency care; however, none have on-site mental health services; people suspected of having mental disorders are referred to the nearby Nampula Central Hospital, a tertiary level unit which has both outpatient and inpatient mental health services. See Table 1 for detailed information about the six study sites. 
Table 1

Study Site Information

\begin{tabular}{|c|c|c|c|c|c|c|}
\hline \multirow[t]{2}{*}{ Health Unit } & \multicolumn{3}{|l|}{ Maputo } & \multicolumn{3}{|l|}{ Nampula } \\
\hline & Mavalane & Albazine & Xipamanine & $\begin{array}{l}1^{\circ} \mathrm{de} \\
\text { Maio }\end{array}$ & $\begin{array}{l}25 \text { de } \\
\text { Setembro }\end{array}$ & Muhala \\
\hline Tier of Care & TerC & PrCMH+ & PrCMH+ & PrCMH- & PrCMH- & PrCMH- \\
\hline Patients/year & 84,948 & 157,642 & 162,239 & 147,240 & 224,232 & 208,440 \\
\hline $\begin{array}{l}\text { MH } \\
\text { Patients/year }\end{array}$ & 3,263 & 2,056 & 1800 & 0 & 0 & 0 \\
\hline \multirow[t]{3}{*}{$\begin{array}{l}\text { MH Specialty } \\
\text { Resources }\end{array}$} & $\begin{array}{l}1 \\
\text { Psychiatrist }\end{array}$ & $\begin{array}{l}1 \\
\text { Psychologist }\end{array}$ & $\begin{array}{l}1 \\
\text { Psychologist }\end{array}$ & None & None & None \\
\hline & $\begin{array}{l}1 \\
\text { Psychologist }\end{array}$ & $1 \mathrm{PT}$ & $1 \mathrm{PT}$ & & & \\
\hline & $3 \mathrm{PT}$ & & & & & \\
\hline
\end{tabular}

\section{Study Population}

Participants were part of a larger study aimed at assessing the validity of mental health screening tools in Mozambican adults. Eligibility criteria included being 18 years of age or older and fluency in Portuguese (self-reported and confirmed by the interviewer). Among 1,515 people who expressed interest in participating, $17(1.1 \%)$ were determined ineligible to participate due to being under 18 years of age ( $\mathrm{n}$ $=7$ ) or not fluent in Portuguese $(n=10)$. For the 1,498 determined to be eligible to participate, $29(1.9 \%)$ declined to provide written informed consent. Of the 1,469 study participants, the present article focuses only on the 612 who were seeking services (including general and/or mental health care) at the study facilities on the day of enrollment (non-patients, or those only accompanying patients, were not included, $n=857$ ). Participants were enrolled from May 16th to December 12th, 2018 (with exclusion of those participants enrolled June 4th -8th in Maputo owing to enrollment specifically targeting people with mental disorders that week).

\section{Measures}

Mental disorders: major depressive disorder, dysthymia, mania, panic disorder, PTSD, alcohol abuse, drug abuse, psychosis, anxiety, somatization and suicide risk were assessed based on a structured diagnostic interview, the Mini International Neuropsychiatric Interview - MINI Plus 4.0.0 $(13,14)$. The MINI is a brief, widely used and diversely validated tool, organized by modules, for diagnosis of mental disorders. The interview lasts between 12 to 30 minutes and can be conducted by trained lay interviewers. The version used in the present study, validated in the Brazilian population (15), was revised with minor local 
language adjustments made by the research team. It was field tested $(n=10)$ by trained research assistants in two health facilities prior to study data collection.

Sociodemographic indicators: Participants self-reported on age, gender, marital status, living situation, education, monthly household income, occupation and religion.

\section{Procedures}

The morning of each day of data collection at each health facility, the research team provided a study description orally to those in the clinic waiting area, where patients gather to await services for the day. The team explained the relevance, general objectives, and processes involved in participating in the research, and invited those interested in participating to speak with a research assistant to be assessed for eligibility. In one facility (Mavalane Hospital), due to its size, the study description was provided in waiting areas of specific health departments serving adults (maternal and child health, adult screening services, emergency room, chronic illnesses); in each of the other facilities there was only one waiting area for all services and the study description was provided there.

For people who expressed interested in participation, study coordinators assessed eligibility, obtained written informed consent, and administered the sociodemographic data questionnaire. A witness to the agreement documented consent in situations where participants were unable to sign their name. Following this, trained interviewers (newly graduated psychologists and final year psychology students) administered the diagnostic instrument (MINI). Providing monetary incentives for research participation is not permitted in Mozambique; however, all participants were offered a snack at the end of the interviews. Study data were collected and managed using REDCap electronic data capture tools hosted at the Foundation for Professional Development (16).

The study procedures were approved by the Ethics Councils of Eduardo Mondlane University (CIBS FM\&HCM/54/2017) and the New York State Psychiatric Institute Institutional Review Board (\#7479).

\section{Data Analysis}

Sociodemographic and MINI diagnostic data were summarized using frequencies and percentages. We first compared (chi-squared analysis) patients from each one of the three types of health care facility (PrCMH+, PrCMH-, TerC) in relation to sociodemographic indicators (age, gender, marital status, living situation, education, monthly household income, occupation, and religion). Second, we determined and compared the frequency of any MINI psychiatric disorder and each MINI psychiatric disorder or suicide risk across health care facility type. We also compared disorders and suicide risk by groups of disorders: common disorders (or CMD, including MDD, Dysthymia, Anxiety, Panic, PTSD or Somatization), severe mental disorder (or SMD, including Mania or Psychosis), substance use disorder (or SUD, including Alcohol or Substance Abuse and Dependence), and suicide risk. Finally, we examined multiple logistic regression models to determine the likelihood that a patient in a primary care unit with a mental health specialist or in tertiary care would present with any mental disorder, CMD, SMD, SUD or suicide risk, adjusting for associated sociodemographic factors. Specifically, we created five models, one for each 
type of mental disorder as a dependent variable (any disorder, CMD, SMD, SUD, and suicide risk), including facility type as an independent variable together with any sociodemographic characteristic found to be significantly associated $(p<0.05)$ with facility type in univariate analysis. We focused on presence of any mental disorder and the four diagnostic categories, as these most directly impact program planning and implementation of services.

\section{Results}

Of the 612 total participants, 215 (35.1\%) were enrolled at the three health facilities in Nampula (PrCMH-), $245(40.0 \%)$ were enrolled at the two primary care facilities in Maputo ( $\mathrm{PrCMH}+)$, and $152(24.8 \%)$ were enrolled at the General Hospital in Maputo (TerC).

Sociodemographic characteristics of participants at each of the three facility types are displayed in Table 2. Chi-squared analyses indicated that all sociodemographic indicators except participant living situation varied significantly by facility type. Participants in TerC were older ( $35.8 \pm 13.4$ years) than participants in $\mathrm{PrCMH}-(30.3 \pm 10.9$ years) and in $\mathrm{PrCMH}+(32.4 \pm 10.5$ years). There were fewer female participants (54.6\%) in TerC than in $\mathrm{PrCMH}-(68.4 \%)$ and $\mathrm{PrCMH}+(60.8 \%)$. Most participants in $\mathrm{PrCMH}-$ were Catholic (46.5\%), whereas in $\mathrm{PrCMH}+(48.4 \%)$ and in TerC most were Evangelical (39.5\%). A smaller portion of participants in TerC were married (39.5\%) than in $\mathrm{PrCMH}+(57.2 \%)$ and $\mathrm{PrCMH}-(58.0 \%)$. More participants in TerC $(21.7 \%)$ and $\mathrm{PrCMH}+(22.0 \%)$ compared to $\mathrm{PrCMH}-(12.6 \%)$ did not complete primary school. As expected, this group had the lowest rates of employment (44.6\%). Many participants at all three facility types were not able to provide information on their household income. Of those that were able to do so, more participants from $\mathrm{PrCMH}-(24.7 \%)$ earned less than the monthly minimum wage than participants in $\mathrm{PrCMH}+(12.2 \%)$ and tertiary care (2.6\%). 
Table 2

Sociodemographic Characteristics by Facility Type

\begin{tabular}{|c|c|c|c|c|c|}
\hline & PrCMH- & PrCMH+ & TerC & & \\
\hline & $\mathrm{N}(\%)$ & $\mathrm{N}(\%)$ & $\mathrm{N}(\%)$ & $x 2$ & $p^{*}$ \\
\hline $\mathrm{N}$ Included & 215 & 245 & 152 & - & - \\
\hline Age (mean, SD) & $30.3(10.9)$ & $32.4(10.5)$ & $35.8(13.4)$ & 12.2 & $<0.000$ \\
\hline Gender, female & $147(68.4)$ & $149(60.8)$ & $83(54.6)$ & 7.4 & 0.03 \\
\hline \multicolumn{6}{|l|}{ Religion } \\
\hline Catholic & $100(46.5)$ & $31(12.7)$ & $45(29.6)$ & 167.2 & $<0.000$ \\
\hline Muslim & $60(27.9)$ & $11(4.5)$ & $9(5.9)$ & & \\
\hline Evangelical & $33(15.3)$ & $118(48.4)$ & $60(39.5)$ & & \\
\hline Other & $22(10.2)$ & $84(34.4)$ & $38(25.0)$ & & \\
\hline \multicolumn{6}{|l|}{ Marital Status } \\
\hline Married/Living as married & $123(57.2)$ & $142(58.0)$ & $60(39.5)$ & 15.1 & 0.001 \\
\hline Not married & $92(42.8)$ & $103(42.0)$ & $92(60.5)$ & & \\
\hline \multicolumn{6}{|l|}{ Living situation } \\
\hline Nuclear +/- Extended Family & $188(87.9)$ & $215(87.8)$ & $134(88.2)$ & 0.01 & 0.99 \\
\hline Alone/Extended Family Only & $26(12.1)$ & $30(12.2)$ & $18(11.8)$ & & \\
\hline \multicolumn{6}{|l|}{ Education } \\
\hline Less than primary & $27(12.6)$ & $54(22.0)$ & $33(21.7)$ & 18.9 & 0.001 \\
\hline Less than secondary & $105(49.1)$ & $138(56.3)$ & $78(51.3)$ & & \\
\hline Secondary and above & $82(38.3)$ & $53(21.6)$ & $41(27.0)$ & & \\
\hline \multicolumn{6}{|l|}{ Occupation } \\
\hline Unemployed & $75(35.2)$ & $62(25.3)$ & $59(39.1)$ & 27.3 & 0.001 \\
\hline Employed & $95(44.6)$ & $149(60.8)$ & $76(50.3)$ & & \\
\hline Other (student, volunteer) & $43(20.2)$ & $34(13.9)$ & $16(10.6)$ & & \\
\hline \multicolumn{6}{|l|}{ Monthly Household Income } \\
\hline No information & 79 (36.7) & $84(34.3)$ & $72(47.4)$ & 54.9 & $<0.000$ \\
\hline
\end{tabular}




\begin{tabular}{|lccl|}
\hline & PrCMH- & PrCMH+ & TerC \\
\hline$\leq 2.800$ (Minimum Wage) & $53(24.7)$ & $30(12.2)$ & $4(2.6)$ \\
\hline $2.801-5.000$ & $44(20.5)$ & $63(25.7)$ & $20(13.2)$ \\
$>5.000$ & $39(18.1)$ & $68(27.8)$ & $56(36.8)$ \\
\hline $\begin{array}{l}\text { PrCMH-, Primary Care without Mental Health Specialists; PrCMH+, Primary Care with Mental Health } \\
\text { Specialists; TerC, Tertiary Care }\end{array}$ \\
\hline
\end{tabular}

Table 3 shows the MINI diagnoses and suicide risk for participants across the three facility types (Table 3). Around half or more of participants at each facility type were diagnosed with at least one mental disorder $(\mathrm{PrCMH}-=48.4 \%, \mathrm{PrCMH}+=50.2 \%, \mathrm{TerC}=62.5 \%)$. Of all participants, $37.7 \%$ were diagnosed with CMD, 29.4\% with SMD, $13.4 \%$ with SUD, and $10.6 \%$ with acute risk of suicide. Major depressive disorder was the most common individual MINI diagnosis, being present in $28.5 \%$ of participants in $\mathrm{PrCMH}-30.5 \%$ of participants in $\mathrm{PrCMH}+$ specialist, and $41.3 \%$ of participants in TerC. Dysthymia and somatization were the least common diagnoses, found in just $0.5 \%$ and $1.3 \%$ of all participants, respectively. Substance dependence and abuse was low across sites (0.9-1.3\%), and over half $(n=7)$ of participants positive for substance dependence and abuse were also positive for alcohol dependence or abuse. Substances abused by those with SUD included: marijuana ( $n=11)$, and other drugs such as hallucinogens and cocaine $(n<3)$. Suicide risk was similar in all settings $(8.9 \%-15.3 \%)$, and $4 \%$ of all participants reported having attempted suicide in the past month. 
Table 3

Mental Disorders by Facility Type

\begin{tabular}{|c|c|c|c|c|c|c|}
\hline & Total & PrCMH- & PrCMH+ & TerC & & \\
\hline & $\mathrm{N}$ & $\mathrm{N}(\%)$ & $\mathrm{N}(\%)$ & N (\%) & $x 2$ & $\mathrm{p}^{*}$ \\
\hline Total N & 612 & 215 & 245 & 152 & - & -- \\
\hline Any MINI Diagnosis & 322 & $104(48.4)$ & $123(50.2)$ & $95(62.5)$ & 8.08 & 0.02 \\
\hline \multicolumn{7}{|l|}{ Diagnostic Groups } \\
\hline CMD & 227 & $77(36.0)$ & $80(33.5)$ & $70(46.7)$ & 7.23 & 0.03 \\
\hline SMD & 177 & $53(24.8)$ & 78 (32.6) & $46(30.7)$ & 3.54 & 0.17 \\
\hline SUD & 81 & $17(7.9)$ & 39 (16.3) & $25(16.7)$ & 8.60 & 0.01 \\
\hline Suicide Risk & 64 & $19(8.9)$ & $22(9.2)$ & $23(15.3)$ & 4.70 & 0.10 \\
\hline \multicolumn{7}{|l|}{ Individual Diagnoses } \\
\hline MDD & 196 & $61(28.5)$ & $73(30.5)$ & $62(41.3)$ & 7.3 & 0.03 \\
\hline Dysthymia & 3 & $3(0.5)$ & $0(0.0)$ & $0(0.0)$ & - & - \\
\hline Anxiety & 57 & $25(11.7)$ & $16(6.7)$ & $16(10.7)$ & 3.62 & 0.16 \\
\hline Panic & 31 & $10(4.7)$ & $11(4.6)$ & $10(6.7)$ & 0.95 & 0.62 \\
\hline PTSD & 41 & $11(5.1)$ & $15(6.3)$ & $15(10.0)$ & 3.5 & 0.18 \\
\hline Somatization & 8 & $1(0.2)$ & $2(0.3)$ & $5(0.8)$ & - & - \\
\hline Mania & 49 & $16(7.5)$ & $21(8.8)$ & $12(8.0)$ & 0.3 & 0.88 \\
\hline Psychosis & 86 & $21(9.8)$ & $45(18.8)$ & $20(13.3)$ & 7.65 & 0.02 \\
\hline Alcohol & 75 & $17(7.9)$ & $34(14.2)$ & $24(16.0)$ & 6.42 & 0.04 \\
\hline Substance & 13 & $2(0.3)$ & $8(1.3)$ & $3(0.5)$ & - & -- \\
\hline
\end{tabular}

Rates of any MINI diagnosis was higher in TerC than PrCMH + and PrCMH-. We also identified a significant difference in distribution of CMD and SUD. Moreover, evaluating each of the individual MINI diagnoses, we found significant variation in the distribution of MDD, psychosis, and alcohol use disorder across the three facility types. 
Table 4 displays results of logistic regression models examining the association between facility type and type of psychiatric diagnosis and suicide risk. The unadjusted odds ratios and $95 \% \mathrm{Cl}$ further the information provided in Table 3, by showing which types of facilities participants had a higher likelihood of having participants with different types of psychiatric disorders compared to those in $\mathrm{PrCMH}$ (reference group). After adjusting for sociodemographic covariates (Table 4), participants in $\mathrm{PrCMH}+$ were more likely to be diagnosed with SMD (OR: $1.85 ; 95 \% \mathrm{Cl}: 1.10-3.11)$ and SUD (OR: $2.79 ; 95 \% \mathrm{Cl}$ : $1.31-5.94)$ than those in PrCMH-. Additionally, participants in TerC were more likely to be diagnosed with any mental disorder (OR: 1.72; 95\% Cl: 1.03-2.87), CMD (OR:1.70; 95\% Cl: 1.01-2.87), and SUD (OR: 2.57; 95\%Cl: 1.14-5.79). There was not a significant difference in suicide risk across facility type.

Table 4

Logistic Regression Models relating MINI Diagnoses with Facility Type, Unadjusted and Adjusted for Sociodemographic Indicators

\begin{tabular}{|c|c|c|c|c|c|}
\hline & Any Disorder & CMD & SMD & SUD & Suicide Risk \\
\hline & OR $(95 \% \mathrm{Cl})$ & OR $(95 \% \mathrm{Cl})$ & OR $(95 \% \mathrm{Cl})$ & OR $(95 \% \mathrm{Cl})$ & OR $(95 \% \mathrm{Cl})$ \\
\hline \multicolumn{6}{|c|}{ Unadjusted } \\
\hline \multicolumn{6}{|l|}{$\begin{array}{l}\text { Facility } \\
\text { Type }\end{array}$} \\
\hline PrCMH- & ref & ref & Ref & ref & ref \\
\hline $\mathrm{PrCMH}+$ & $\begin{array}{l}1.08(0.75- \\
1.56)\end{array}$ & $\begin{array}{l}0.90(0.61- \\
1.32)\end{array}$ & $\begin{array}{l}1.47(0.98- \\
2.22)\end{array}$ & $\begin{array}{l}2.26(1.24- \\
4.13)\end{array}$ & $\begin{array}{l}1.04(0.54- \\
1.98)\end{array}$ \\
\hline TerC & $\begin{array}{l}1.78(1.16- \\
2.71)\end{array}$ & $\begin{array}{l}1.56(1.01- \\
2.38)\end{array}$ & $\begin{array}{l}1.34(0.84- \\
2.14)\end{array}$ & $\begin{array}{l}2.31(1.20- \\
4.46)\end{array}$ & $\begin{array}{l}1.85(0.97- \\
3.55)\end{array}$ \\
\hline \multicolumn{6}{|c|}{ Adjusted for sociodemographic indicators } \\
\hline \multicolumn{6}{|l|}{$\begin{array}{l}\text { Facility } \\
\text { Type }\end{array}$} \\
\hline PrCMH- & ref & ref & Ref & ref & ref \\
\hline $\mathrm{PrCMH}+$ & $\begin{array}{l}0.97(0.62- \\
1.53)\end{array}$ & $\begin{array}{l}0.79(0.49- \\
1.28)\end{array}$ & $\begin{array}{l}1.85(1.10- \\
3.11)\end{array}$ & $\begin{array}{l}2.79 \\
5.94)\end{array}$ & $\begin{array}{l}0.89(0.41- \\
1.93)\end{array}$ \\
\hline TerC & $\begin{array}{l}1.72(1.03- \\
2.87)\end{array}$ & $\begin{array}{l}1.70(1.01- \\
2.87)\end{array}$ & $\begin{array}{l}1.53(0.87- \\
2.68)\end{array}$ & $\begin{array}{l}2.57(1.14- \\
5.79)\end{array}$ & $\begin{array}{l}1.73(0.79- \\
3.80)\end{array}$ \\
\hline
\end{tabular}

\section{Discussion}

This paper described the frequency of mental disorders among people seeking health and/or mental health services at multiple health care units in the cities of Maputo and Nampula, Mozambique. These 
health care units reflect the different types of facilities in the public health system in Mozambique where patients would routinely access health and mental health care: primary care facilities with and without a mental health specialist and tertiary care facilities with a mental health specialist. As potential differences in mental disorder frequency across types of health care facility could simply reflect the sociodemographic profile of patients accessing each type of facility, these characteristics were also assessed.

Our study had three main findings. First, mental disorders were extremely common in the population studied; $53 \%$ of participants had at least one mental disorder, ranging from $48 \%$ in $\mathrm{PrCMH}$ - to $63 \%$ in tertiary care. Second, the frequency of psychiatric disorders was higher in TerC than PrCMH + or a PrCMH-. Suicide risk was the only type of mental health problem that did not differ among facility types. Third, even though there were sociodemographic differences among patients seeking care in the different types of health care facilities studied, these differences did not fully explain differences in frequency of mental disorder across facility types, except for severe mental disorders.

\section{Mental Disorders in the Study Population}

Based on MINI diagnoses, over half of our study population had at least one mental disorder. The most common single disorder identified was major depressive disorder, found in $32 \%$ of study participants. Although the nationwide prevalence of mental illness is not well established in Mozambique, previous research has demonstrated rates of depressive symptoms in the population between $14 \%$ and $19 \%$ (17, 18). The difference in estimated prevalence in the general population and our study sample is consistent with reports from other countries that people with MDD are more likely to seek general health services. This is in line with previous research establishing the bi-directional relationship between mood disorders and physical illness (19) and the association between depression and health care-seeking in sub-Saharan Africa (20) and worldwide.

The annual report from the Mozambican Ministry of Health's Mental Health Program indicated the most common diagnosis in outpatient mental health services is epilepsy (57\%), followed by psychosis (15\%), substance use disorders (7\%) and only finally mood disorders (6\%) (21). In Mozambique, as in many other LMICs, epilepsy cases are treated mainly in mental health services. This high percentage of epilepsy diagnoses in mental health care is likely to be due to higher awareness and prioritization of these disorders among patients and providers, following the nationwide implementation of the mhGAP epilepsy program $(6,22)$. The high frequency of depression detected in the present study coupled the low frequency found in the national reports suggests that many with depression are not being identified and connected with mental health services even if they seek general care, emphasizing the need for educating both patients and providers on the recognition and treatment of depression.

Estimates from the WHO have placed Mozambique as the southern African country with the highest number of suicides (23). In our study sample, we found an $11 \%$ prevalence of moderate to high suicide risk, and, even more striking, that $4 \%$ of participants reported having made a suicide attempt in past 
month. Existing data indicate that suicide attempts recorded in health facilities account for less than $1 \%$ of the chief complaints that patients present with $(21,24)$. Considering that our study was conducted in 3 weeks and included only a few health facilities in two provinces, and reports are annual and country-wide, our data suggests that there may be significant underreporting of cases in Mozambique. Underreporting of cases may be due to limited care seeking for suicide risk due to stigma $(25,26)$ and/or failures in detection or registration of cases by providers, highlighting the need to implement suicide risk screening procedures and standardize the registration system (27).

\section{Rates of Mental Disorders at Different Types of Health Facilities}

We found that mental disorders overall were significantly more frequent in tertiary care than primary care with and without a mental health specialist. This was also seen in a study from Nigeria where more than $80 \%$ of mental health patients were served at tertiary medical facilities (28). Looking at specific disorder categories, we found that participants with CMD and SUD were more likely to be found in TerC than in $\mathrm{PrCMH}-$, even after adjusting for sociodemographic variables. For $\mathrm{CMD}$, this finding may be due to symptoms of CMD commonly co-occurring with somatic features of severe physical conditions, such as shortness of breath or fatigue (29), leading providers in primary care to refer patients to either be treated or undergo further evaluation in facilities with more resources (i.e., TerC) (6). Moreover, there is a strong relationship between $\mathrm{CMD}$ and severe physical illness related to disability resulting from the disease and its social and economic impacts (30). This may also be true regarding SUD. Indeed, people may be often seen at the tertiary level because of the physical complications related to the substance abuse, rather than the SUD itself. Specifically, they may seek care at or be referred to tertiary facilities to access specialists to better treat related complications. (31).

Interestingly, distribution of SMD across the different types of health facilities was not significantly different prior to adjusting for sociodemographic covariates. However, after controlling for covariates, we found that SMD were more frequent in $\mathrm{PrCMH}+$. This may be because the population recognizes symptoms of SMD, such as psychosis, as a mental health issue and seek mental health services at the primary care level, as in some communities (all facilities in the Nampula site, in this study) it is the nearest location to access formal health care $(32,33)$. In this case, it is possible that people with the knowledge that this type of disorder ultimately requires treatment at the quaternary level (large psychiatric hospital covering a large area) present themselves at the health facilities of the primary level in order to more easily access the quaternary level through ambulances. It may be easier for them to use transport from the health services than transportation resources they may not have. Importantly, additional research is needed to determine why people with SMD are more likely to be found in primary care settings in Mozambique, which may also be the case in other low-income settings.

\section{Sociodemographic characteristics of the three health facilities}


Comparing the study population across the three types of health facilities, we found statistically significant differences in age, gender, marital status, education, occupation, income, and religion. While these sociodemographic differences may contribute to care seeking behavior and mental illness, they did not fully explain the differences in the distribution of diagnoses by facility type in our sample despite suggesting a significant influence regarding SMD.

This study had some limitations. First, our convenience sample included patients who volunteered to participate after learning the study objectives, which may have resulted in participant selection bias. However, despite being a sample of convenience, non-patients and those whose recruitment was highly targeted (specifically in services for severe mental disorders) were not included. Additionally, the location of the health facilities that were part of the study does not include a rural region, where access to care is more difficult, which may have also limited the diversity of the study population. Moreover, based on a cross-sectional study of a selected sample, we cannot assume causality of the associations identified. Finally, the diagnostic instrument used was validated in the Portuguese language but not validated for the Mozambican population. However, DSM criteria, on which the MINI is based, are the standard for diagnosing and treating mental illness in Mozambique, and all participants were screened for Portuguese fluency and understanding at inclusion.

\section{Conclusions}

We identified high rates of mental illness among patients seeking health and mental health care at primary and tertiary care facilities in Mozambique. Significantly higher rates of CMD and SUD were found in TerC, and SMD and SUD were more common in $\mathrm{PrCMH}+$ than PrCMH-. Together, our results emphasize the need for general practitioners to be well-trained in the detection, referral, and management of people with a broad spectrum of mental disorders. This study also highlights the need to develop practical, and effective mental health services across levels of care in Mozambique. Finally, nationwide reporting systems must be improved/implemented to support the country in decision-making to effectively target resources to improve mental health treatment.

\section{Abbreviations}

$\mathrm{MH}$, mental health; CMD, common mental disorders; SMD, severe mental disorders; SUD, substance use disorders; $\mathrm{PrCMH}+$, primary care with mental health specialists; $\mathrm{PrCMH}-$, primary care without mental health speciailsts; TerC, LMIC, low- and middle-income countries; tertiary care; $\mathrm{Cl}$, confidence interval; DSM, Diagnostic and Statistical Manual for Mental Disorders.

\section{Declarations}

\section{Ethics approval and consent to participate}


All participants provided written informed consent as approved by the Ethics Council of Eduardo Mondlane University (CIBS FM \& HCM/54/2017) and the New York State Psychiatric Institute Institutional Review Board (\#7479).

\section{Availability of data and materials}

The datasets generated and/or analyzed during the current study are not publicly available due to regulations of the Mozambican government but are available from the corresponding author on reasonable request.

\section{Competing interests}

Dr. Oquendo receives royalties from the Research Foundation for Mental Hygiene for the commercial use of the C-SSRS, is a scientific consultant to Fundacion Jimenez Diaz in Madrid and owns equity in Mantra, Inc. Her family owns stock in Bristol Myers Squibb. The rest of the authors declare that they have no competing interests.

\section{Funding}

This study was supported by NIMH grants U19MH113203, T32MH096724, and K01MH120258; Fogarty International Center grant D43TW009675; and NIAAA grant R01AA025947.

\section{Authors' contributions}

LG, KLL, WF, PS, MAO, JJM, MLW, and CSD contributed to study conception and design and data acquisition. KLL analyzed data. LG, KLL, WF, AF, PS, and CSD contributed to data interpretation. All authors made substantial contributions to manuscript preparation and revision. All authors read and approved the final manuscript.

\section{Acknowledgements}

We would like to express our gratitude to all the participants of the study. The success of this study was possible due to the commitment of a large team composed of professionals at the Department of Mental Health in the Ministry of Health and in the cities of Maputo and Nampula who participated in data collection at the health facilities, as well as the D43 Fogarty Fellows from Mozambique for their contributions to the study implementation. We also would like to thank Prof. Ilana Pinsky, Charl Bezuidenhout, Phuti Ngwepe, and Whety Sarmento for all the technical support. A special thanks to Prof. Marcelo Feijó de Mello, Angel Rojas and Carolina Ziebold from São Paulo Federal University (UNIFESP) for their valuable support in research mentoring. We could not end without addressing our special appreciation to Prof. Mohsin Sidat and Prof. Esperança Comiche for all the technical support at the beginning of this study.

\section{References}


1. Wainberg ML, Scorza P, Shultz JM, Helpman L, Mootz JJ, Johnson KA, et al. Challenges and Opportunities in Global Mental Health: a Research-to-Practice Perspective. Current Psychiatry Reports. 2017.

2. World Bank. GNI per capita, Atlas method (current US\$) [Internet]. World Bank Group US. 2018 [cited 2020 Apr 3]. p. 1. Available from: https://data.worldbank.org/indicator/NY.GNP.PCAP.CD? locations=MZ\&view=chart

3. INE. Estatísticas e Indicadores Sociais - Instituto Nacional de Estatistica [Internet]. INSTITUTO NACIONAL DE ESTATISTICA - Moçambique. 2017 [cited 2020 Jun 5]. Available from: http://www.ine.gov.mz/estatisticas/estatisticas-demograficas-e-indicadores-sociais/estatisticas-eindicadores-sociais

4. IHME. Mozambique Profile [Internet]. Seattle, WA: IHME, University of Washington. 2017 [cited 2020 Jun 2]. Available from: http://www.healthdata.org/mozambique

5. WHO. WHO | Mental Health ATLAS 2017 [Internet]. WHO. 2017 [cited 2020 Jun 8]. Available from: https://www.who.int/mental_health/evidence/atlas/mental_health_atlas_2017/en/

6. Santos PF, Wainberg ML, Caldas-de-Almeida JM, Saraceno B, Mari J de J. Overview of the mental health system in Mozambique: Addressing the treatment gap with a task-shifting strategy in primary care. Int J Ment Health Syst. 2016;

7. OECD. OECD Data [Internet]. OECD. 2018 [cited 2020 Sep 16]. Available from: https://data.oecd.org/

8. Oquendo MA, Duarte C, Gouveia L, Mari JJ, Mello MF, Audet CM, et al. Building capacity for global mental health research: challenges to balancing clinical and research training. The Lancet Psychiatry. 2018.

9. MISAU. ESTRATÉGIA E PLANO DE ACÇÃO PARA A SAÚDE MENTAL 2016 - 2026. Maputo Mozambique; 2016.

10. Kebede MA, Anbessie B, Ayano G. Prevalence and predictors of depression and anxiety among medical students in Addis Ababa, Ethiopia. Int J Ment Health Syst. 2019 May 6;13(1).

11. Patel V, Simbine APF, Soares IC, Weiss HA, Wheeler E. Prevalence of severe mental and neurological disorders in Mozambique: a population-based survey. Lancet. 2007;

12. Lovero KL, Basaraba C, Khan S, Suleman A, Mabunda D, Feliciano P, dos Santos P, Fumo W, Greene MC, Fiks Salem A, Mootz JJ, Mocumbi MO, Duarte CS, Gouveia L, Oquendo MA, Wall MM WM. Brief Screening Tool for Stepped-Care Management of Mental and Substance Use Disorders. (under review).

13. Amorim P. Mini International Neuropsychiatric Interview (MINI): validação de entrevista breve para diagnóstico de transtornos mentais. Rev Bras Psiquiatr. 2000 Sep;22(3):106-15.

14. Sheehan D V., Lecrubier Y, Sheehan KH, Amorim P, Janavs J, Weiller E, et al. The Mini-International Neuropsychiatric Interview (M.I.N.I.): The development and validation of a structured diagnostic psychiatric interview for DSM-IV and ICD-10. In: Journal of Clinical Psychiatry [Internet]. 1998 [cited 2020 Jun 5]. p. 22-33. Available from:

https://www.psychiatrist.com/jcp/article/pages/1998/v59s20/v59s2005.aspx 
15. de Azevedo Marques JM, Zuardi AW. Validity and applicability of the Mini International Neuropsychiatric Interview administered by family medicine residents in primary health care in Brazil. Gen Hosp Psychiatry [Internet]. 2008 Jul [cited 2020 Mar 19];30(4):303-10. Available from: http://www.ncbi.nlm.nih.gov/pubmed/18585532

16. Harris PA, Taylor R, Thielke R, Payne J, Gonzalez N, Conde JG. Research electronic data capture (REDCap)-A metadata-driven methodology and workflow process for providing translational research informatics support. J Biomed Inform. 2009 Apr;42(2):377-81.

17. Audet CM, Wainberg ML, Oquendo MA, Yu Q, Blevins Peratikos M, Duarte CS, et al. Depression among female heads-of-household in rural Mozambique: A cross-sectional population-based survey. J Affect Disord. 2018 Feb 1;227:48-55.

18. Halsted S, Ásbjörnsdóttir KH, Wagenaar BH, Cumbe V, Augusto O, Gimbel S, et al. Depressive symptoms, suicidal ideation, and mental health care-seeking in central Mozambique. Soc Psychiatry Psychiatr Epidemiol. 2019 Dec 1;54(12):1519-33.

19. Katon WJ. Epidemiology and treatment of depression in patients with chronic medical illness. Dialogues Clin Neurosci. 2011;13(1):7-24.

20. Barkin RL, Schwer WA, Barkin SJ. Recognition and management of depression in primary care: A focus on the elderly. A pharmacotherapeutic overview of the selection process among the traditional and new antidepressants. Am J Ther. 2000;7(3):205-26.

21. MISAU. RELATÓRIO ANUAL DE SAÚDE MENTAL - Moçambique. Maputo - Mozambique; 2018.

22. Dos Santos PF, Cumbe V, Gouveia ML, De Fouchier C, Teuwen D, Dua T. Implementation of mhGAP in Mozambique: Integrating epilepsy care into the primary health care system. Int J Ment Health Syst. 2019;

23. WHO. Preventing suicide:a global imperative. Geneva World Heal Organ. 2014;

24. BH W, M R-B, V C, D R, M N, K S. Suicide Attempts and Deaths in Sofala, Mozambique, From 2011 to 2014. Crisis. 2016;37(6).

25. Bifftu BB, Dachew BA, Tiruneh BT, Guracho YD. Prevalence of suicidal ideation, suicidal attempt and completed suicide in Ethiopia: A systematic review and meta-analysis protocol. Syst Rev [Internet]. 2019 Mar 22 [cited 2020 Jun 5];8(1):72. Available from: https://systematicreviewsjournal.biomedcentral.com/articles/10.1186/s13643-019-0986-8

26. Muthemba R. Estigma e percepções dos médicos de Clínica Geral sobre a doença mental e o suicídio [Internet]. Universidade Nova de Lisboa; 2014 [cited 2020 Jun 5]. Available from: https://run.unl.pt/handle/10362/15214

27. Jordans M, Rathod S, Fekadu A, Medhin G, Kigozi F, Kohrt B, et al. Suicidal ideation and behaviour among community and health care seeking populations in five low- and middle-income countries: A cross-sectional study. Epidemiol Psychiatr Sci. 2018 Aug 1;27(4):393-402.

28. Mohammed Said J, Jibril A, Isah R, Beida O. Pattern of Presentation and Utilization of Services for Mental and Neurological Disorders in Northeastern Nigeria: A Ten-Year Study. Psychiatry J [Internet]. 
2015 [cited 2020 Apr 3];2015:1-5. Available from:

https://www.hindawi.com/journals/psychiatry/2015/328432/

29. Bifftu BB, Takele WW, Guracho YD, Yehualashet FA. Depression and Its Help Seeking Behaviors: A Systematic Review and Meta-Analysis of Community Survey in Ethiopia. Depression Research and Treatment. 2018.

30. Daré LO, Bruand PE, Gérard D, Marin B, Lameyre V, Boumédiène F, et al. Co-morbidities of mental disorders and chronic physical diseases in developing and emerging countries: A meta-analysis. BMC Public Health. 2019 Mar 13;19(1):1-12.

31. Zewdu S, Hanlon C, Fekadu A, Medhin G, Teferra S. Treatment gap, help-seeking, stigma and magnitude of alcohol use disorder in rural Ethiopia. Subst Abus Treat Prev Policy. 2019;

32. Roberts T, Miguel Esponda G, Krupchanka D, Shidhaye R, Patel V, Rathod S. Factors associated with health service utilisation for common mental disorders: A systematic review. BMC Psychiatry. 2018 Aug 22;18(1):1-19.

33. Gouveia L, Massanganhe H, Mandlate F, Mabunda D, Fumo W, Mocumbi AO, et al. Family reintegration of homeless in Maputo and Matola: A descriptive study. Int J Ment Health Syst. 2017;11(1):1-6. 